\title{
Effect of Different Chemical Treatments on Shelf Life of Kinnow Fruits
}

\author{
Pooja Ahlawat, Suman Bala* and Jitender Kumar \\ ${ }^{1}$ Department of Botany and Plant Physiology, CCS HAU, Hisar, Haryana, India
}

*Corresponding author

\begin{abstract}
A B S T R A C T
Keywords

Kinnow, Shelf life, coating, Gum Arabic, Sugars and total soluble solids

Article Info

Accepted:

26 February 2018

Available Online:

10 March 2018

Kinnow mandarin is an important fruit of India but is highly perishable and liable to be spoiled under ambient conditions. Present investigation was conducted to study the effect various concentrations of Gum Arabic, Calcium Lactate and Glycerin and their different combination on shelf life of Kinnow fruits during storage at room temperature. Physiological loss in weight increased with increase in the period of storage. Total soluble solids, total sugars and reducing sugars were also increased up to 49 days of storage period in all treatments. However non-reducing sugar content was decreased up to $7^{\text {th }}$ day thereafter it increased up to $49^{\text {th }}$ day of storage. All coatings were effective to check the physiological loss in weight and maintain the sugar content of the kinnow fruits. However Gum Arabic 10\% coating was the most effective to minimize the physiological loss in weight and maintained the quality parameters at all period of storage.
\end{abstract}

\section{Introduction}

Kinnow mandarins are rich in ascorbic acid (13-54 mg per $100 \mathrm{~g}$ of edible portion) and calcium $(25-46 \mathrm{mg}$ per $100 \mathrm{~g}$ of edible portion). Due to these quality traits, it is in high demand in India and exotic markets. Consumer demands for kinnow picks up during February and March when there is no fruit available in market for juice purposes moreover in the peak period of production (December and January) because of cold temperature there is not a huge demand by the consumer and it comes in the glut in the market so, the farmers cannot get reasonable prices for their produce. So, there is a dire need that this fruit should be made available in the month of February and March by storing fruit in storage conditions or on trees. On tree storage is not feasible because there is granulation in the fruit so there is a need to invent some devices which are easily affordable by the farmers, so that the fruit can be made available in the off season (i.e. February and March) that will also help to avoid the glut in the production season. The postharvest losses can be minimized by extension of shelf life through checking the 
rate of transpiration, respiration, microbial infection and protecting membranes from disorganization (Bisen and Pandey, 2008). The foresaid objectives can be achieved to some extent by use of edible coatings, gel, oil, lipid, starch, packaging and wrapping materials and different type of storage used as postharvest treatments. Edible coatings are applied as thin coating that forms a protective barrier around fruit and can be consumed along with the coated product. Coatings make good oxygen and lipid barrier at low to intermediate relative humidity because the polymers can effectively make hydrogen bonds (Sihag et al., 2005). However, no systematic work has been done to study the comparative effect of gum Arabic, calcium lactate and glycerin alone as well as in combination on physiological changes in kinnow fruits, so, present experiment was conducted to find out the effective postharvest treatments of gum arabic, calcium lactate and glycerin or in proper concentration to enhance the shelf life of Kinnow fruits.

\section{Materials and Methods}

Present experiment was conducted in the laboratory of department of Botany and and Plant Physiology, CCS Haryana Agricultural University, Hisar. The experiment was designed in completely randomized design. Mature Kinnow fruits of uniform size were harvested with the help of secateurs keeping small intact pedicel with each fruit from the orchard of the department of Horticulture, CCS Haryana Agricultural University, Hisar. Kinnow fruits were cleaned with muslin cloth and were dipped in aqueous solutions of Gum Arabic (5\%), Gum Arabic (10\%), Calcium lactate $(1 \%)$, Calcium Lactate (3\%), Glycerin (2.5\%), Gum Arabic (5\%)+Glycerin (2.5\%), Glycerin $(2.5 \%)+$ Glycerin $(2.5 \%)$, Calcium lactate $(1 \%)+$ Glycerin $(2.5 \%)$ and Calcium lactate $(3 \%)+$ Glycerin $(2.5 \%)$ for 10 minutes and were dried in shade thereafter were wrapped in cling film. Two $\mathrm{kg}$ fruits were packed in each cardboard box and all the treatments were replicated four times. Fruits of all treatments were stored at room temperature. Three replicates were used for estimating physiological loss in weight (PLW). Three fruits at random were taken from fourth replication for analysis of parameters such as TSS, total sugars and reducing sugar in fresh fruits and at seven days of interval up to $49^{\text {th }}$ day. PLW was calculated by the methods of Srivastava and Tandon (1968). Total soluble solids in sapota fruits were estimated by using Abbe's hand refractometer $\left(0-32^{0}\right.$ Brix $)$. Total sugars and reducing sugars were estimated by the method of Paleg (1960). Non-reducing sugars were determined by subtracting the amount of reducing sugar from the total sugars and expressed as percent.

\section{Results and Discussion}

Physiological loss in weight PLW increased with increasing period of storage in all the treatments as indicated in table 1. This is obvious as fruit is living entity after the harvest and various physiological processes especially the respiration and transpiration are going on which utilizes the substrate present in the fruit so the fruit losses its weight because of these processes. Similar results of increasing physiological loss in weight during storage has also been reported in Grapes (Shiri et al., 2011), Jambu air (Tehrani et al., 2011), Jujube fruits (Xing et al., 2015; Shahi et al., 2015), sapota (Bala and Kumar, 2017) and Mango (Carrillo et al., 2000; Gill et al., 2015). On $7^{\text {th }}$ day of storage, minimum PLW was observed in fruits treated with gum arabic $10 \%(0.12 \%)$ followed by gum arabic $5 \%$ $(0.15 \%)$ whereas maximum PLW was observed in control fruits $(0.76 \%)$. On $21^{\text {th }}$, $28^{\text {th }}, 35^{\text {th }}$ and $42^{\text {th }}$ day similar trend was observed. On $49^{\text {th }}$ day of storage, minimum PLW was recorded in fruits coated with Gum 
Arabic 10\% (6.36\%) followed by Gum Arabic $5 \%$ coated fruits $(6.77 \%)$ and maximum PLW was observed in control $(9.90 \%)$. This is obvious because all these treatments made additional surface coating over the surface of fruits which made a barrier for diffusion of gases and restricted various physiological processes. Among different coatings, minimum PLW was observed with Gum Arabic $10 \%$ coatings on all days of storage (from 0 to 49days). This may be because of the reason that Gum Arabic adhered to the surface of the fruit and formed a stable permeable coating which restricted the physiological process to greater extent and they reduced PLW to greater extent. Similar results were reported in Tomato (Ali et al., 2010), in Banana (Maqbool et al., 2011) and in Mango (de S. Medeiros et al., 2012) fruits.

\section{Total soluble solids (TSS)}

Total soluble solid content of the fruits as presented in table 2 increased with increasing period of storage in all the treatments. Minimum TSS was observed on initial day of storage that is $10.1{ }^{0} \mathrm{Brix}$ which increased to $12.28^{0}$ Brix on $49^{\text {th }}$ day of storage. This might be either due to water loss or due to conversion of organic acids into sugars which might have resulted in increase in total soluble solids concentration. Increase in TSS in fruits during storage period has also been reported by Shiri et al., (2011) in Table Grapes, Nath et al., (2012) in Pear, Patil and Shanmugasundaram (2015) in Banana, Shahi et al., (2015) in Ber, Bala et al., (2017a) and Kumar et al., (2016) in Sapota. Among the treatments, minimum TSS was observed in fruits coated with Gum Arabic 10\% (11.01 ${ }^{0}$ Brix) followed by fruits treated with Gum Arabic 5\% (11.05 ${ }^{0}$ Brix). Maximum TSS was observed in control fruits $\left(11.30{ }^{0}\right.$ Brix $)$ followed by Glycerin coated fruits (11.29 ${ }^{0}$ Brix). All the treatments were effective to reduce the TSS content of fruits to different extent. Among the interactions, minimum TSS was observed in fruits coated with Gum Arabic 5\% on Zero day of storage that is 10.07 ${ }^{0}$ Brix whereas maximum TSS was observed in control fruits $\left(12.43{ }^{0}\right.$ Brix $)$ on $49^{\text {th }}$ day of storage. This might be because coatings formed an excellent barrier around the fruits which resulted in decrease in water losses. These results are in accordance with the findings of Al-Juhaimi (2014) and Ali et al., (2010) in Tomato fruits.

\section{Total sugars}

As data presented in table 3 total sugar content followed the similar trend as followed by TSS during storage as well as in different treatments. This clearly indicates that TSS content of fruits is due to the sugar present in the fruits.

\section{Reducing sugars}

Reducing sugar content increased with increasing period of storage in all the treatments during storage however, all the treatments were effective to alter the reducing sugar content (Table 4). Increase in reducing sugars during storage might be due to nonclimacteric nature of kinnow fruit, so no fresh synthesis of reducing sugars takes place. Increase in reducing sugar content during storage might also be due to increase in water loss. Increase in reducing sugars with increasing period of storage has also been reported in strawberry (Moing and Renaud, 2001), Tangerine fruits (Roongruangsri et al., 2013), sapota (Bala et al., 2017b) and Kagzi lime (Selvaraj and Raja, 2000). Among the treatments, maximum reducing sugar was observed in control fruits $(5.07 \%)$. This could be attributed to the lack of coatings in control fruits which might have resulted in increased evapo-transpirational losses. Minimum reducing sugar content was observed in fruits coated with Gum Arabic 10\% (4.55\%) followed by Gum Arabic 5\% (4.62\%). 
Table.1 Effect of different treatments on physiological loss in weight (\%) in Kinnow fruits during storage at room temperature

\begin{tabular}{|l|}
\hline Treatments \\
\hline Gum Arabic (5\%) \\
\hline Gum Arabic $(\mathbf{1 0} \%)$ \\
\hline Calcium Lactate $(\mathbf{1} \%)$ \\
\hline Calcium Lactate $(3 \%)$ \\
\hline Glycerin $(2.5 \%)$ \\
\hline Gum Arabic $(5 \%)+$ Glycerin $(2.5 \%)$ \\
\hline Gum Arabic $(10 \%)+$ Glycerin $(2.5 \%)$ \\
\hline Calcium Lactate $(1 \%)+$ Glycerin $(2.5 \%)$ \\
\hline Calcium Lactate $(3 \%)+$ Glycerin $(2.5 \%)$ \\
\hline Control \\
\hline C.D. at $5 \%$ \\
\hline
\end{tabular}

\begin{tabular}{|c|c|c|c|c|c|c|}
\hline 7 & 14 & 21 & 28 & 35 & 42 & 49 \\
\hline 0.15 & 1.09 & 2.01 & 3.25 & 4.84 & 5.94 & 6.77 \\
\hline 0.12 & 1.19 & 1.93 & 2.85 & 4.26 & 5.52 & 6.36 \\
\hline 0.35 & 1.62 & 2.84 & 4.08 & 5.20 & 6.77 & 7.98 \\
\hline 0.42 & 1.53 & 2.62 & 3.46 & 4.96 & 6.23 & 7.52 \\
\hline 0.65 & 2.53 & 3.76 & 5.23 & 6.28 & 8.16 & 9.43 \\
\hline 0.32 & 1.58 & 3.14 & 4.02 & 4.98 & 6.15 & 7.34 \\
\hline 0.43 & 1.13 & 2.50 & 3.41 & 5.00 & 6.02 & 7.11 \\
\hline 0.46 & 1.53 & 2.33 & 3.82 & 5.44 & 6.53 & 7.57 \\
\hline 0.57 & 2.24 & 3.02 & 4.12 & 5.87 & 6.76 & 7.52 \\
\hline 0.76 & 2.84 & 4.03 & 5.68 & 6.95 & 8.45 & 9.90 \\
\hline 0.04 & 0.05 & 0.06 & 0.10 & 0.10 & 0.17 & 0.23 \\
\hline
\end{tabular}

Table.2 Effect of different treatments on total soluble solids content ( ${ }^{0}$ Brix $)$ in Kinnow fruits during storage at room temperature

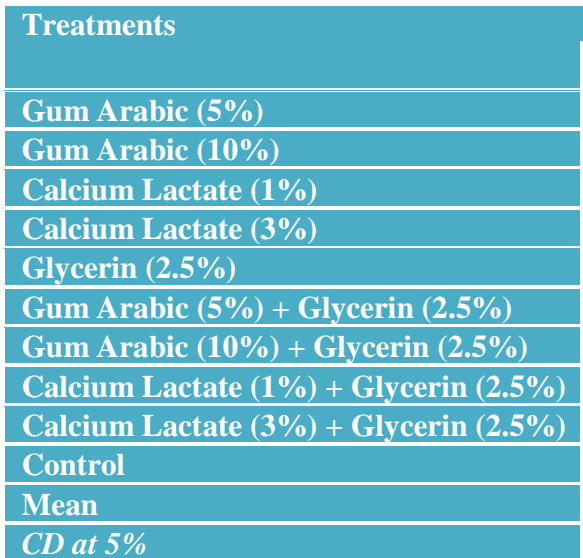

\begin{tabular}{|c|c|c|c|c|c|c|c|c|}
\hline $\mathbf{0}$ & $\mathbf{7}$ & $\mathbf{1 4}$ & $\mathbf{2 1}$ & $\mathbf{2 8}$ & $\mathbf{3 5}$ & $\mathbf{4 2}$ & $\mathbf{4 9}$ & Mean \\
\hline 10.07 & 10.30 & 10.50 & 10.80 & 11.27 & 11.50 & 11.77 & 12.20 & $\mathbf{1 1 . 0 5}$ \\
\hline 10.10 & 10.33 & 10.53 & 10.80 & 11.13 & 11.40 & 11.67 & 12.13 & $\mathbf{1 1 . 0 1}$ \\
\hline 10.10 & 10.43 & 10.60 & 11.03 & 11.30 & 11.63 & 12.03 & 12.33 & $\mathbf{1 1 . 1 8}$ \\
\hline 10.13 & 10.43 & 10.60 & 10.90 & 11.23 & 11.50 & 11.90 & 12.30 & $\mathbf{1 1 . 1 3}$ \\
\hline 10.10 & 10.63 & 10.80 & 11.10 & 11.43 & 11.70 & 12.13 & 12.40 & $\mathbf{1 1 . 2 9}$ \\
\hline 10.10 & 10.40 & 10.63 & 11.00 & 11.33 & 11.50 & 11.90 & 12.23 & $\mathbf{1 1 . 1 4}$ \\
\hline 10.10 & 10.40 & 10.43 & 10.90 & 11.23 & 11.50 & 11.80 & 12.23 & $\mathbf{1 1 . 0 8}$ \\
\hline 10.10 & 10.50 & 10.60 & 10.83 & 11.33 & 11.60 & 11.93 & 12.17 & $\mathbf{1 1 . 1 3}$ \\
\hline 10.10 & 10.53 & 10.73 & 11.00 & 11.33 & 11.60 & 11.83 & 12.33 & $\mathbf{1 1 . 1 8}$ \\
\hline 10.13 & 10.63 & 10.80 & 11.13 & 11.43 & 11.73 & 12.13 & 12.43 & $\mathbf{1 1 . 3 0}$ \\
\hline $\mathbf{1 0 . 1 0}$ & $\mathbf{1 0 . 4 6}$ & $\mathbf{1 0 . 6 2}$ & $\mathbf{1 0 . 9 5}$ & $\mathbf{1 1 . 3 0}$ & $\mathbf{1 1 . 5 7}$ & $\mathbf{1 1 . 9 1}$ & $\mathbf{1 2 . 2 8}$ & \\
\hline
\end{tabular}

Table.3 Effect of different treatments on total sugars (\%) in Kinnow fruits during storage at room temperature
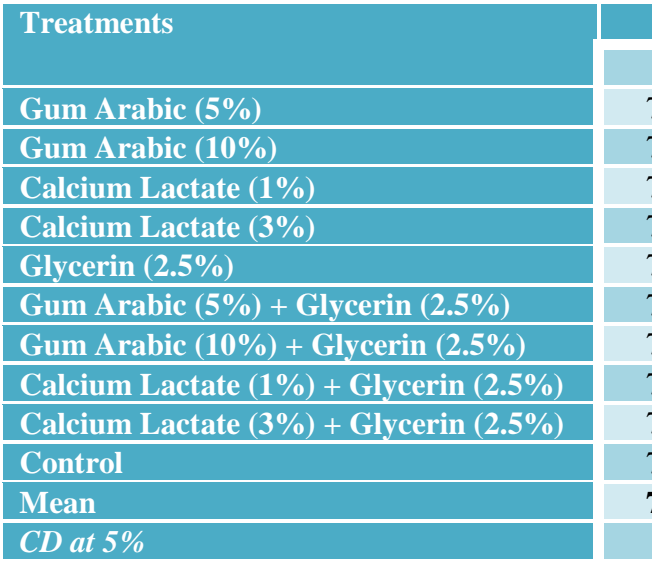

Days of storage

\begin{tabular}{|c|c|c|c|c|c|c|c|c|}
\hline $\mathbf{0}$ & $\mathbf{7}$ & $\mathbf{1 4}$ & $\mathbf{2 1}$ & $\mathbf{2 8}$ & $\mathbf{3 5}$ & $\mathbf{4 2}$ & $\mathbf{4 9}$ & Mean \\
\hline 7.91 & 8.52 & 8.72 & 8.99 & 9.33 & 9.60 & 9.87 & 10.41 & $\mathbf{9 . 1 7}$ \\
\hline 7.91 & 8.45 & 8.65 & 8.92 & 9.13 & 9.33 & 9.67 & 10.07 & $\mathbf{9 . 0 2}$ \\
\hline 7.91 & 8.79 & 9.20 & 9.33 & 9.53 & 9.80 & 10.14 & 10.48 & $\mathbf{9 . 4 0}$ \\
\hline 7.91 & 8.58 & 8.85 & 9.06 & 9.33 & 9.53 & 9.87 & 10.41 & $\mathbf{9 . 1 9}$ \\
\hline 7.91 & 8.92 & 9.13 & 9.33 & 9.53 & 9.73 & 10.07 & 10.55 & $\mathbf{9 . 4 0}$ \\
\hline 7.91 & 8.79 & 8.99 & 9.19 & 9.53 & 9.67 & 10.21 & 10.68 & $\mathbf{9 . 3 7}$ \\
\hline 7.91 & 8.52 & 8.79 & 8.99 & 9.19 & 9.46 & 9.87 & 10.34 & $\mathbf{9 . 1 4}$ \\
\hline 7.91 & 8.99 & 9.33 & 9.53 & 9.67 & 9.94 & 10.27 & 10.82 & $\mathbf{9 . 5 6}$ \\
\hline 7.91 & 8.45 & 8.86 & 9.13 & 9.40 & 9.73 & 10.14 & 10.55 & $\mathbf{9 . 2 7}$ \\
\hline 7.91 & 9.12 & 9.46 & 9.60 & 9.87 & 10.14 & 10.34 & 10.88 & $\mathbf{9 . 6 7}$ \\
\hline $\mathbf{7 . 9 1}$ & $\mathbf{8 . 7 1}$ & $\mathbf{9 . 0 0}$ & $\mathbf{9 . 2 1}$ & $\mathbf{9 . 4 5}$ & $\mathbf{9 . 6 9}$ & $\mathbf{1 0 . 0 5}$ & $\mathbf{1 0 . 5 2}$ & \\
\hline
\end{tabular}


Table.4 Effect of different treatments on reducing sugars content (\%) in Kinnow fruits during storage at room temperature

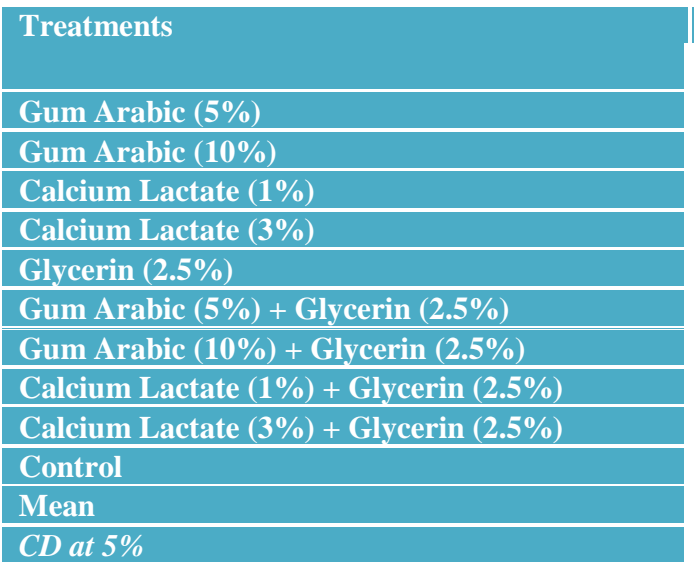

\begin{tabular}{|c|c|c|c|c|c|c|c|c|}
\hline \multicolumn{7}{|c|}{ Days of storage } \\
\hline $\mathbf{0}$ & $\mathbf{7}$ & $\mathbf{1 4}$ & $\mathbf{2 1}$ & $\mathbf{2 8}$ & $\mathbf{3 5}$ & $\mathbf{4 2}$ & $\mathbf{4 9}$ & Mean \\
\hline 3.45 & 4.19 & 4.33 & 4.60 & 4.80 & 5.00 & 5.21 & 5.51 & $\mathbf{4 . 6 2}$ \\
\hline 3.45 & 3.99 & 4.26 & 4.53 & 4.73 & 4.94 & 5.14 & 5.34 & $\mathbf{4 . 5 5}$ \\
\hline 3.45 & 4.39 & 4.53 & 4.80 & 4.98 & 5.34 & 5.54 & 5.75 & $\mathbf{4 . 8 5}$ \\
\hline 3.45 & 4.19 & 4.46 & 4.73 & 4.93 & 5.20 & 5.61 & 5.78 & $\mathbf{4 . 8 1}$ \\
\hline 3.45 & 4.39 & 4.80 & 5.00 & 5.20 & 5.41 & 5.34 & 5.61 & $\mathbf{4 . 9 0}$ \\
\hline 3.45 & 4.53 & 4.59 & 4.87 & 5.00 & 5.20 & 5.41 & 5.68 & $\mathbf{4 . 8 4}$ \\
\hline 3.45 & 4.33 & 4.46 & 4.66 & 4.87 & 5.07 & 5.27 & 5.48 & $\mathbf{4 . 7 0}$ \\
\hline 3.45 & 4.58 & 4.80 & 4.80 & 5.14 & 5.34 & 5.55 & 5.81 & $\mathbf{4 . 9 3}$ \\
\hline 3.45 & 4.40 & 4.66 & 4.87 & 5.07 & 5.27 & 5.47 & 5.75 & $\mathbf{4 . 8 7}$ \\
\hline 3.45 & 4.60 & 4.87 & 5.07 & 5.34 & 5.48 & 5.75 & 5.58 & $\mathbf{5 . 0 7}$ \\
\hline $\mathbf{3 . 4 5}$ & $\mathbf{4 . 3 6}$ & $\mathbf{4 . 5 8}$ & $\mathbf{4 . 7 9}$ & $\mathbf{5 . 0 1}$ & $\mathbf{5 . 2 3}$ & $\mathbf{5 . 4 3}$ & $\mathbf{5 . 6 7}$ & \\
\hline & & & $\mathbf{T}=\mathbf{0 . 2 3} \mathbf{D = 0 . 2 1} \mathbf{T} \times \mathbf{D}=\mathbf{0 . 7 0}$ & & & \\
\hline
\end{tabular}

Table.5 Effect of different treatments on non-reducing sugars content (\%) in Kinnow fruits during storage at room temperature

\begin{tabular}{|c|c|c|c|c|c|c|c|c|c|}
\hline \multirow[t]{2}{*}{ Treatments } & \multicolumn{9}{|c|}{ Days of storage } \\
\hline & $\mathbf{0}$ & 7 & 14 & 21 & 28 & 35 & 42 & 49 & Mean \\
\hline Gum Arabic (5\%) & 4.46 & 4.33 & 4.39 & 4.39 & 4.53 & 4.60 & 4.66 & 5.00 & 4.55 \\
\hline Gum Arabic (10\%) & 4.46 & 4.46 & 4.39 & 4.39 & 4.39 & 4.39 & 4.53 & 4.73 & 4.47 \\
\hline Calcium Lactate (1\%) & 4.46 & 4.39 & 4.66 & 4.53 & 4.56 & 4.46 & 4.59 & 4.73 & 4.55 \\
\hline Calcium Lactate (3\%) & 4.46 & 4.39 & 4.39 & 4.33 & 4.40 & 4.33 & 4.26 & 4.63 & 4.39 \\
\hline Glycerin $(2.5 \%)$ & 4.46 & 4.53 & 4.33 & 4.33 & 4.33 & 4.33 & 4.73 & 4.93 & 4.50 \\
\hline Gum Arabic (5\%) + Glycerin $(2.5 \%)$ & 4.46 & 4.26 & 4.39 & 4.33 & 4.53 & 4.46 & 4.80 & 5.00 & 4.53 \\
\hline Gum Arabic $(10 \%)+$ Glycerin $(2.5 \%)$ & 4.46 & 4.19 & 4.33 & 4.33 & 4.33 & 4.39 & 4.59 & 4.87 & 4.44 \\
\hline Calcium Lactate $(1 \%)+$ Glycerin $(2.5 \%)$ & 4.46 & 4.42 & 4.53 & 4.73 & 4.53 & 4.60 & 4.73 & 5.00 & 4.60 \\
\hline Calcium Lactate $(3 \%)+$ Glycerin $(2.5 \%)$ & 4.46 & 4.05 & 4.19 & 4.26 & 4.32 & 4.46 & 4.66 & 4.80 & 4.40 \\
\hline Control & 4.46 & 4.53 & 4.59 & 4.53 & 4.53 & 4.66 & 4.59 & 5.01 & 4.63 \\
\hline Mean & 4.46 & 4.36 & 4.42 & 4.41 & 4.44 & 4.47 & 4.62 & 4.87 & \\
\hline
\end{tabular}

Calculated by subtraction method, so CD was not taken

This might be due because of coatings on fruit surface restricted the PLW. Similar increase in reducing sugar content during storage has also been reported by Maqbool et al., (2011) in Banana fruits.

\section{Non-reducing sugars}

However, data predicted (Table 5) that nonreducing sugar content decreased with increasing period of storage up to $7^{\text {th }}$ day thereafter it increased up to $49^{\text {th }}$ day of storage. So, there was no fresh synthesis of non-reducing sugars and already existed nonreducing sugars might have been utilized in the metabolism. So the total non-reducing sugars content decreased. These results are also in conformity with the results of Doreyappa and Huddar (2001) and Mann and Dhillon (1974) in Mango. Minimum non reducing sugar content was recorded in fruits treated with Calcium Lactate 3\% (4.39\%) followed by Calcium Lactate $(3 \%)+$ Glycerin $(2.5 \%)$ treated fruits $(4.47 \%)$ and maximum non reducing sugar content was observed in control fruits $(4.63 \%)$ followed by Calcium Lactate $(1 \%)+$ Glycerin $(2.5 \%)$ treated fruits $(4.60 \%)$. Maximum increase in non-reducing sugar content was observed in control fruits. Minimum non reducing sugar content was 
observed in Calcium Lactate 3\% coated fruits. This might be due to decrease in respiration and transpiration process and these coatings might have delayed the conversion of polysaccharides into sugars. Similar results have also been reported by Moayednia et al., (2010) in Strawberry.

It may be concluded that all coatings were effective to check the PLW and maintained the sugar content of the kinnow fruits. However Gum Arabic 10\% coating was the most effective to minimize the PLW and retained the sugars content at all period of storage.

\section{References}

Ali, A., Maqbool, M., Ramachandran, S. and Alderson, P. G. 2010. Gum arabic as a novel edible coating for enhancing shelf-life and improving postharvest quality of tomato (Solanum lycopersicum L.) fruit. Postharvest Biology and Technology. 58: 42-47.

Al-Juhaimi, F. Y. 2014. Physicochemical and sensory characteristics of arabic gumcoated tomato (Solanum lycopersicum L.) fruits during storage. Journal of Food Processing and Preservation. 38: 971-979.

Bala, S., Kumar, J. And Duhan, S. 2017. Biochemical changes in pulp and peel of sapota (Manilkara zapota L.) at different stages of ripening. Research on crops. 18(2): 260-263.

Bala. S. and Kumar, J. 2017a. Effect of ethylene absorbent $\left(\mathrm{KMnO}_{4}\right)$ on shelflife of sapota (Manilkara zapota L.). Green farming. 8(5): 1227-1232.

Bala. S. and Kumar, J. 2017b. Effect of drying methods on acidity and sugar content of sapota (Manilkara zapota L.). Journal of Plant Development Sciences. 9(4): 329-333.
Bisen, A. and Pandey, S. K. 2008. Effect of post-harvest treatment on biochemical composition and organoleptic quality in Kagzi lime fruit during storage. Journal of Horticulture Science. 3: 53-56.

Carrillo, L.A., Ramirez-Bustamante, F., Valdez-Torres, J. B., Rojas-Villegas, R. and Yahia, E. M. 2000. Ripening and quality changes in Mango fruit as affected by coating with an edible film. Journal of Food Quality. 23: 479-486.

De S. Medeiros, B.G., Pinheiro, A.C., Carneiro-da-Cunha, M.G. and Vicente, A.A., 2012. Development and characterization of a nano multilayer coating of pectin and chitosanevaluation of its gas barrier properties and application on 'Tommyatkins' mangoes. Journal of Food Engineering. 110: 457-464.

Doreyappa, I.N. and Huddar, A.G. 2001. Studies on ripening changes in Mango fruits. Journal of Food Science and Technology. 38: 135-137.

Gill, P.P.S., Jawandha, S.K., Kaur, N., Singh, N. and Sangwan, A. 2015. Effect of LDPE packaging on post-harvest quality of Mango fruits during low temperature storage. The Bioscan. 10: 177-180.

Kumar, A., Chauhana, A.S., Ravib, R. and Kudachikar, V.B. 2016. Influence of pretreatments and storage condition on the quality of Sapota (Achras zapota) fruit and on its processed product marmalade. International Journal of Current Sciences. 19: 133-145.

Mann, S.S. and Dhillon, B.S. 1974. Effect of ethrel and calcium carbide on ripening of Mangoes. Progessive Horticulture Journal. 19: 139-141.

Maqbool, M., Ali, A., Alderson, P.G., Zahid, N. and Siddiqui, Y. 2011. Effect of a novel edible composite coating based on gum arabic and chitosan on biochemical and physiological 
responses of banana fruits during cold storage. Journal of Agricultural and Food Chemistry. 59: 5474-5482.

Moayednia, N., Ehsani, M. R., Emamdjomeh, Z., Mazaheri Asadi, M., Mizani, M. and Mazaheri, A. F. 2010. A note on the effect of calcium alginate coating on quality of refrigerated strawberries. Irish Journal of Agricultural and Food Research. 49: 165-170.

Moing, A. and Renaud, C. 2001. Biochemical changes during fruit development of four strawberry cultivars. Journal of American Society for Horticultural Sciences. 126: 394-403.

Nath, A., Deka, B. C., Singh, A., Patel, R. K., Paul, D., Misra, L. K. and Ojha, H. 2012. Extension of shelf life of pear fruits using different packaging materials. Journal of Food Science and Technology. 49: 556-563.

Paleg, L.G. 1960. Physiological effect of Gibberellic acid on carbohydrates metabolism and amylase activity of barley endosperm. Plant Physiology. 35: 293-299.

Patil, S.K. and Shanmugasundaram, S. 2015. Physico-chemical changes during ripening of Monthan Banana. International Journal of Technology Enhancements and Emerging Engineering Research. 3: 18-21.

Roongruangsri, W., Rattanapanone, N., Leksawasd, N. and Boonyakiat, D. 2013. Influence of storage conditions on physico-chemical and biochemical of two Tangerine cultivars. Journal of Agricultural Sciences. 5: 70-84.

Selvaraj, Y. and Raja, M. E. 2000. Biochemistry of ripening of kagzi lime
(Citrus aurantifolia Swingle) fruits. Indian Journal of Horticulture. 57: 1-8.

Shahi, M., Rastegar, S. and Khankahdani, H. H. 2015. Effects of essential oil and calcium chloride on quantitative and qualitative features Ziziphus mauritiana during storage. International Journal of Plant, Animal and Animal Sciences. 5, 25-31.

Shiri, M. A., Ghasemnezha, D, M., Bakhshi, D. and Dadi, M. 2011. Changes in phenolic compounds and antioxidant capacity of fresh-cut table grape (Vitis vinifera) cultivar 'Shahaneh' as influence by fruit preparation methods and packagings. Australian Journal of Crop Science. 5: 1515-1520.

Sihag, R. P., Behiwal, L. S. and Mehta, P. K. 2005. Effect of post-harvest application of potassium permanganate on shelf life of Peach fruit. Haryana Journal of Horticulture Science. 34: 259-260.

Srivastava, M. P. and Tandon, D. K. 1968. Influence of temperature in Botryoplodia rot of citrus and Sapodilla. Indian Phytopathology. 21: 195-197.

Tehrani, M., Chandran, S., Hossain, A. B. M. S. and Boyce, A. N. 2011. Postharvest physico-chemical and mechanical changes in jambu air (Syzygium aqueum Alston) fruits. Australian Journal of Crop Science. 5: 32-38.

Xing, Y., Lin, H., Cao, D., Xu, Q., Han, W., Wang, R., Che, Z. and Li. X. 2015. Effect of chitosan coating with cinnamon oil on the quality and physiological attributes of China jujube fruits. Biomedical Research International. 15: 1-10.

\section{How to cite this article:}

Pooja Ahlawat, Suman Bala and Jitender Kumar. 2018. Effect of Different Chemical Treatments on Shelf Life of Kinnow Fruits. Int.J.Curr.Microbiol.App.Sci. 7(03): 3209-3215. doi: https://doi.org/10.20546/ijcmas.2018.703.371 